\title{
Study on Anomie of University Teachers' Network Language
}

\author{
Xueming Yang \\ College of Communication, GuangXi University for Nationalities, Nanning, 530008, China
}

\begin{abstract}
Keywords: Anomie of network language, University teachers, Communication, Concealment
\end{abstract}
\begin{abstract}
At the present stage, with the continuous development of network, the teaching mode in the educational circle of our country has changed greatly. By using the network language during teaching, teachers can not only improve the teaching efficiency, but also intensify the communication with students and facilitate the establishment and harmonization of the relation with students, which provides teachers with the guarantee of timely solving students' problems. Practice shows that network makes people's thinking and inter-personal communication patterns more flexible; meanwhile, network brings great impact on people's life. However, network has certain concealment, which leads to certain pollution of the network environment and has apparently affected some cognition of contemporary students. At present, the anomie of university teachers' network language has become an important problem. If this problem cannot be effectively solved for a long time, it will certainly bring certain influence on students' future development. This paper mainly studies the anomie of university teachers' network language, with the purpose of improving the effective application of network language by university teachers.
\end{abstract}

\section{Introduction}

With the continuous development of network, the network language is widely used in people's life, which adds certain harmony and brings great fun to people's life. However, the network environment has certain concealment, resulting in frequent use of vulgar network language by many netizens and consequently bringing great pollution to network environment and negative impact to teenagers' mental health and healthy growth. The anomie of university teachers' network language is also a kind of common phenomenon. Due to the lack of understanding of network language, many teachers use it improperly during their teaching process, thus the phenomenon of anomie occurs frequently.

\section{Analysis on definition of network language in universities}

In the condition of increasingly common network, network language becomes popular gradually among people and gets developed quickly. Network language is different from the traditional form of language, because it is not bound by traditional factors. Currently, there are many forms of definitions for network language and different forms of research achievements. Some people define the network language as a kind of language used in network communication, which is mainly divided into three categories: some strongly professional terms related to network, some special terms related to network, and a kind of language used by netizens or students in chat rooms or BBS. Some People thought that "net language" is a product of network, because people often express their thoughts and emotions via network that has become part of people's life, which is greatly different from emotional expression in our real life. To further embody the characteristics of emotional expression in network, people have created the "net language". Some other people thought that network language is a kind of language that is often used in computer network and related to the computer network language, including dialogues with respect to network communication language such as images and symbols on the webpage, words and network technology language.

To sum up the definitions above, the network language, which is different from life language, is an important medium for people's communication in the network environment, and it includes not only Chinese characters, but also expressions, symbols, images and many other patterns. This makes the network language richer and more diversified, and makes its application more flexible. 


\section{Analysis on characteristics of network language}

Network language has certain characteristics, mainly including:

\section{Changeable form, jocularity and vividness}

Network freedom provides people with unlimited creative space, which further raises people's interest in creation, continuous network innovation, and release of various original and witty network language. The creation of network language gives new meanings to our Chinese characters and makes their application wider and more interesting. Some new words can be also created in the network space; for example, "Pai Zhuan ("knock with a brick", means reviling people)" and some other words are more vivid and contains certain charm of ridicule. As the existence of these jocular and vivid words makes the network full of humor, they become widely popular among people.

\section{Serious colloquialism and obvious tendency towards westernization}

In fact, most of network language is transformed from the local language. For instance, "Jiang Zi" is a homonymic tone of "Zhe Yang Zi" (means "like this"). Due to the restraint by English during the use by netizens in reality, many English contents are mixed together, containing a lot of network language. However, most of people cannot understand such network language, and do not think it makes sense.

\section{Vulgarization of network language}

As everyone knows, the virtuality of network determines that many netizens conceal their real identities, which provides netizens with the space and opportunity to release their social pressure and leads to vulgarization of network language. Many low-quality netizens will often use some bad or vulgar words during their communications, making the network environment greatly polluted and bringing negative impact to the future development of many teenagers.

Such characteristics of network language result in common anomie of university teachers' network language and failure to teach students via effective utilization of network language, which brings certain obstacles to the future development of university students.

\section{Analysis on necessity of standardizing the network language}

Though the rich and innovative network language can bring certain fun to our life, enrich the originally boring words and makes our life increasingly wonderful and vivid, its appearance also brings some problems, especially the serious anomie of network language. Some people once commented the network language like this: The appearance of network language impacted our national language to some extent, and even resulted in certain area of "burn" to our national language. Due to the influence by American culture, some words and context contain the ambience of American culture, such as: paying more attention to simplicity and convenience, pursuing open and direct expression pattern, and having strong desire for language self-expression, which deviate from traditional culture.

Some people thought that the network language does not have the characteristics of our traditional language, and even lacks the legitimacy and normalization. Therefore, those netizens and students with narrow scope of knowledge will be affected by the anomie of network language. These people have a low-level ability of identification, and may easily behave improperly under the influence of anomalous network language. Thus, if the vulgar and falsely-created network language cannot be controlled timely and effectively, it will certainly bring great damage to traditional language and affect the future development of our students and teenagers.

\section{Analysis on strategies for correcting and standardizing university teachers' network language}

According to the analysis above, university teachers' network language has certain problems to be solved via correction and standardization strategies, to guarantee the more reasonable and effective utilization of university teachers' network language. Therefore, the following points shall be satisfied: 


\section{Analysis on standardization principle}

Insisting on the standardization principle to standardize university teachers' network language includes:

Insisting on the principle of guidance

Network language is characterized by universality and profoundness, which is decided by the characteristics of network itself[1]. Generally, network involves many fields; therefore, the standardization of network language needs the support of the government, so as to guarantee the standard use of network language, fully intensify the implementation of education and management works, and ensure the cleanness of network environment.

Insisting on the principle of multiple perspectives

The appearance of a language phenomenon is not completed only via a kind of language, it will be affected by many aspects in the society. Thus, in the process of analyzing the influence of network language, it is required to find out the source that leads to anomie of network language, combines the characteristics of our Chinese language and adopt feasible methods to standardize university teachers' network language starting from perspectives of culture, education and folk custom, so as to create a favorable network environment for university students.

Insisting on the principle of interaction

As an important link of communication between people in the network world, the reasonability and standardization of network language are very necessary. To guarantee the reasonability and standardization of network language, people need to consciously standardize their language in the process of creating and using the network language, and use it in a proper environment; then, a healthy and positive network environment can be guaranteed. University teachers' network language should be also like this; in the process of using the network language, teachers should pay attention to regarding interaction as an important principle, so as to provide students with a healthier network language.

Insisting on the principle of sublation

Anomie of network language is inevitable; therefore, in the process of using network language, we should not escape from the anomie phenomenon, but learn to face the anomie phenomenon of network language and adopt positive and effective methods to solve this problem; in this process, one thing to note is that we should select the essence and discard the dross of the network language ${ }^{[2]}$, namely, introduce good network language into our traditional cultural education, which will not only arouse university students' interest in learning, but also make students positively participate in teaching activities, facilitate the establishment of harmonious relationship between teachers and students, provide students with a healthy network language environment, let students use the network language in a civilized way, and reduce the anomie phenomenon of network language. The vulgar network language should be sublated and prevented from spreading. Following the newspapers and periodicals, TV and other media, the appearance of network has brought a great impact on teenagers' growth. Network contains both good and bad things; therefore, network language users should treat network language with a mixed perspective, rather than fully accept or negate it. Insisting on the principle of sublation is very necessary.

\section{Analysis on strategies for correcting university teachers' network language}

Correction strategy shall start from the following points:

Strengthening the standardization consciousness of university teachers and netizens

Netizens are major users of network language, thus it is very necessary to strengthen the standardization consciousness of netizens. It is also required to strengthen the standardization consciousness of university teachers when they use the network language, so that teachers can provide students with more standard and reasonable network language ${ }^{[3]}$. Besides, it is required to strengthen university teachers' self-discipline consciousness, to guarantee that teachers can consciously use standard vocabularies to express their ideas when communicating with students, which will not only unconsciously transfer the concept of standard network language to students, but also standardize their own network language and avoid the appearance of randomly-created words. 
Giving full play to universities' educational function

Schools shoulder the important responsibility for education; therefore, in the process of network utilization by teenagers, schools need to blend the network language education into the teaching for corresponding standardization and guide teenagers to correctly use standard network language, so that students can use the network language in a favorable network language environment. Meanwhile, universities also need to guide students to read more books in daily life, so as to increase their knowledge and consequently make their language expression more profound and standard. Universities need combine the network language standardization with the campus culture construction, for instance, periodically organizing students to carry out activities including network language standardization and network error correction, so as to allow students forming a good habit in network language utilization under the premise of improving students' ability to identify network language.

Making full use of the transmission function of media

In the work of network language standardization, media transmission plays an important role. In fact, the media work has a extremely high requirement on self-regulation. Therefore, standardizing the network language via the transmission function of media is very effective ${ }^{[4]}$. In the media reporting, it is required to avoid the abuse of network language with the purpose of attracting more eyes; therefore, standardizing the network language via the transmission function of media plays a very important role. Besides, in the operation of mainstream network media such as Baidu and other network platforms, cooperation with other relevant department is required. Meanwhile, it is required to carry out the the publicity and education of network language standardization, remind netizens of using the network language in a civilized and standard way within network public space, etc.

For a nation, its language can fully indicate the psychological characteristics of the nation, which is an important part of national culture and has relation to future development of the nation. Although the appearance of network language has driven the our cultural development to some extent, it is produced on the important basis of Chinese language $\mathrm{e}^{[5]}$; therefore, network language standardization is also related to the development of our language culture. To facilitate the more standard and harmonious development and inheritance of our language culture, the standardized management of network language is very necessary.

\section{Conclusion}

With the continuous development of the times, network has become an indispensable part of people's life, and its existence has brought some fun to people's life and broadened people's horizons to some extent. However, with the appearance of network language, our traditional language has suffered from certain impact. This paper mainly analyzes the meanings and definitions of network language in universities, the necessity of standardizing network language, and strategies for standardizing and correcting university teachers' network language, and has identified the vulgarization of current-stage network language, which polluted the network environment to some extent. If this problem cannot be solved timely, our traditional language culture will certainly suffer from certain negative impact. Besides, the anomie of university teachers' network language also exists, which is adverse to students' future development; therefore, it becomes urgent to solve this problem.

\section{Acknowledgments}

This paper is a special subject for educational planning and language work study in Guangxi.

\section{References}

[1] Li Lili. Enlightenment of Network Language's Post-modern Features on Teachers' Humor. Journal of Chifeng University (Philosophy and Social Science Edition), 2014, (4): 259-260. 
[2] He Yanping. How Should Teachers Treat Network Language in Middle School Students' Compositions. Secondary School Curriculum Coaching (Teaching Research), 2012, 6(12):68-68.

[3] Fu Yifei. Investigation and Analysis on Network Language Utilization in Dalian. Journal of Daliann Maritime University (Social Science Edition), 2013, 12(3):109-112.

[4] Tao Youbin. When Network Language Comes - A Tentative Study on Language Standardization in Middle School Compositions. New Classes (Middle School), 2014, (10):116-116.

[5] Jin Xin. Personality Defects Indicated by Teachers' Network Language. New Plot for Mandarim, 2007, (12): 46-47. 